\title{
Research on respiration characteristics of fresh cut purple cabbage
}

\author{
Zhu Li ${ }^{1,2, a}$, Wang Lu ${ }^{1,2, a}$, Wang Dan ${ }^{1, a}$, Ma Yue ${ }^{1, a}$, Zhao Xiao-yan ${ }^{1, a}$, \\ 1.Beijing Vegetable Research Center, Beijing Academy of Agriculture and Forestry Science, \\ Beijing Key Laboratory of Agricultural Products of Fruits and Vegetables Preservation and \\ Processing, Key Laboratory of Biology and Genetic Improvement of Horticultural Crops (North \\ China) and Key Laboratory of Urban Agriculture (North), Ministry of Agriculture, Beijing 100097 \\ China. 2. Food College of Shehezi University.) \\ azhaoxiaoyan@nercv.org
}

Keywords: Fresh cut purple cabbage; Respiratory rate;Kinetic respiration rate model;

Abstract: In order to give useful information for the appropriate packaging conditions, respiration characteristics of fresh cut purple cabbage was clarified. The respiratory rate were determined by using closed system method. The changes of headspace gas concentrations in tank was determined, and the respiration rate model was established with no competitive inhibition Michaelis enzyme kinetics equation. The results showed that the respiratory rate of fresh cut purple cabbage was positively correlated with temperature. The lowest $\mathrm{R}^{2}$ of the mathematical models of respiratory rate about fresh cut celery were 0.84 which indicating that the model has a very good fitting. It can predict the change of respiratory rate from the model. It will give useful theoretical and technical support for gas packaging design of fresh cut purple cabbage.

\section{Introduction}

The vegetable is still alive and in metabolism after processing ${ }^{[1]}$. Purple cabbage accelerated cell respiration and the metabolism through the physical cutting, so decreased the shelf life ${ }^{[2]}$. Modified Atmosphere packaging is widely used in fruit and vegetable storage, by adjusting the packaging of oxygen $\left(\mathrm{O}_{2}\right)$ and carbon dioxide $\left(\mathrm{CO}_{2}\right)$ components. The respiration rate of vegetable is the key to study packaging design ${ }^{[3]}$. In recent years, A large number of researchers focused on the respiration rate of common vegetables, but few reports on the respiration of purple cabbage. In this paper, the respiration rate model of fresh cut cabbage was established to predict the respiration intensity changes, which will provide useful reference for modified atmosphere packaging design.

\section{Materials and methods}

\section{Materials}

Freshly purple cabbage were obtained from a local market in Beijing. Damaged products were discarded. Laboratory and cutting tool need sterilize before cutting. The whole process keep under the condition of $16^{\circ} \mathrm{C}$.

\section{Preparation of product}

Remove the surface sediment and then cut in block (Length $5 \pm 1 \mathrm{~cm}$, wide $5 \pm 1 \mathrm{~cm}$ ). Then, the samples were disinfected in chlorinated water $(100 \mathrm{ppm})$ for $1.5 \mathrm{~min}$. Finally remove surface water using vegetable dehydrator.

\section{Respiration rate analysis}

The respiration rate was calculated by following equation ${ }^{[4-5]}$ : 


$$
\begin{gathered}
R_{\mathrm{CO}_{2}}=\frac{\left[\mathrm{CO}_{2}\right]^{n}-\left[\mathrm{CO}_{2}\right]^{n-1}}{\Delta t} \cdot \frac{V_{f}}{W} \\
R_{\mathrm{O}_{2}}=\frac{\left[\mathrm{O}_{2}\right]^{n}-\left[\mathrm{O}_{2}\right]^{n-1}}{\Delta t} \cdot \frac{V_{f}}{W}
\end{gathered}
$$

Where: $\mathrm{R}_{\mathrm{CO} 2}-\mathrm{CO}_{2}$ generation rate, $\mathrm{mL} /(\mathrm{kg} \mathrm{h}) ; \mathrm{R}_{\mathrm{O} 2}-\mathrm{O}_{2}$ consumption rate, $\mathrm{mL} /(\mathrm{kg} \mathrm{h}) ; \mathrm{V}_{\mathrm{f}}-$ Free volume, $\mathrm{mL} ; \mathrm{W}$ - mass, $\mathrm{kg} ; \triangle \mathrm{t}$ - time interval, $\mathrm{h}$.

\section{Establishment of respiration rate model}

Refer no competitive Michaelis-Menten(M-M) equation put forward by Mathooko ${ }^{[6]}$, The relationship of respiration rate and $\mathrm{O}_{2}$ concentration Represented as :

$$
R=\frac{V_{m}\left[O_{2}\right]}{K_{m}+\left[1+C O_{2}\right] /\left[K_{i}\right]\left[O_{2}\right]}
$$

Where: $\mathrm{Km}, \mathrm{Ki}, \mathrm{Vm}-$ constant of the equation; $\left[\mathrm{O}_{2}\right]-\mathrm{O}_{2}$ concentation, \%; $\left[\mathrm{CO}_{2}\right]-\mathrm{CO}_{2}$ concentration, \%; R-respiratory rate $\mathrm{mL} /(\mathrm{kg} \mathrm{h})$.

\section{Results and Discussion}

\section{Headspace gas composition in the tank}

The Headspace gas composition in the tank of purple cabbage is shown in fig. 1, The curve shown that headspace $\mathrm{O}_{2}$ concentration decrease with the storage time (fig.1(A)), while increase in the headspace $\mathrm{CO}_{2}$ concentration was observed in Fig. 1 (B). Moreover, there are significant differences between different temperature conditions of storage. $\mathrm{O}_{2}$ concentration decreased fasteast under $30{ }^{\circ} \mathrm{C}$, which reduced to zero within $30 \mathrm{~h}$. $\mathrm{CO}_{2}$ increased to $15.8 \%$ within $20 \mathrm{~h}$ under $30^{\circ} \mathrm{C}$. storage at $4{ }^{\circ} \mathrm{C}, \mathrm{O}_{2}$ concentration only reached $18 \%$, and $\mathrm{CO}_{2}$ concentration is about $15.8 \%$ within $72 \mathrm{~h}$.
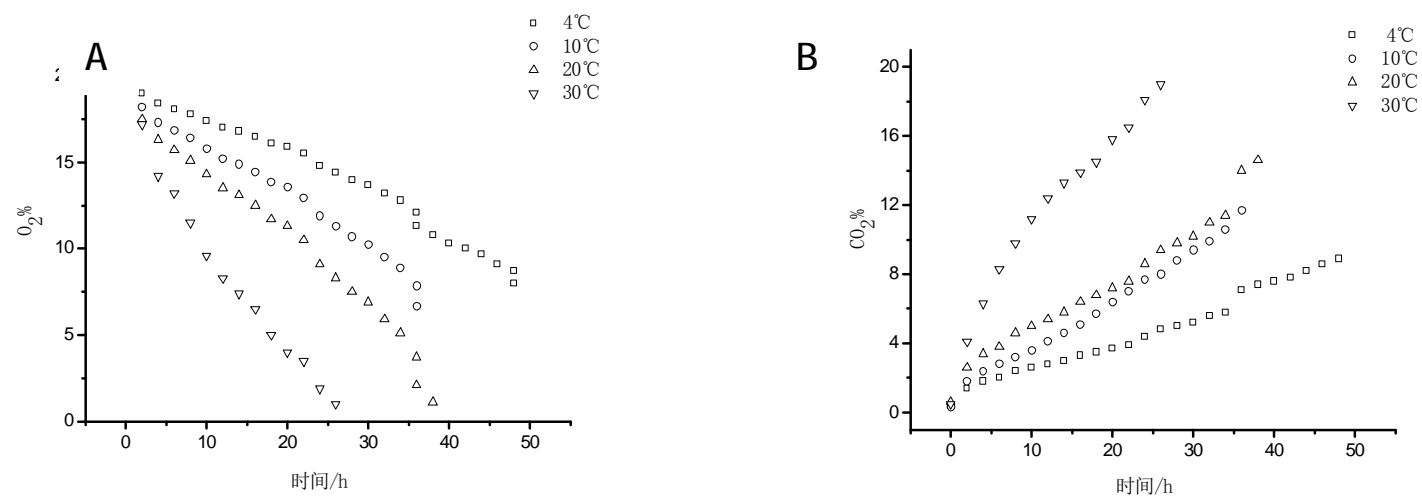

Fig.1 Changes of oxygen concentration(A) and dioxide concentration(B) of fresh-cut Purple cabbage at different temperature

\section{Respiration rate}

Respiration rate of purple cabbage was calculated by using the headspace gas composition in the tank, which was shown in fig. 2. $\mathrm{O}_{2}$ consumption rate and $\mathrm{CO}_{2}$ generated rate decreas with storage time , and it reduced fastest within the first $10 \mathrm{~h}$, then gradually tend to be balanced. Moreover, 
different temperature have the same trend, and at the low temperature represent more significant. Combined with figure 1 , fresh cut purple cabbage respiratory metabolism was inhibited at low oxygen and high carbon dioxide environment, thus reduced the respiration rate is a good way to conduct the fresh cut purple cabbage storage, and prolong it's shelf life.
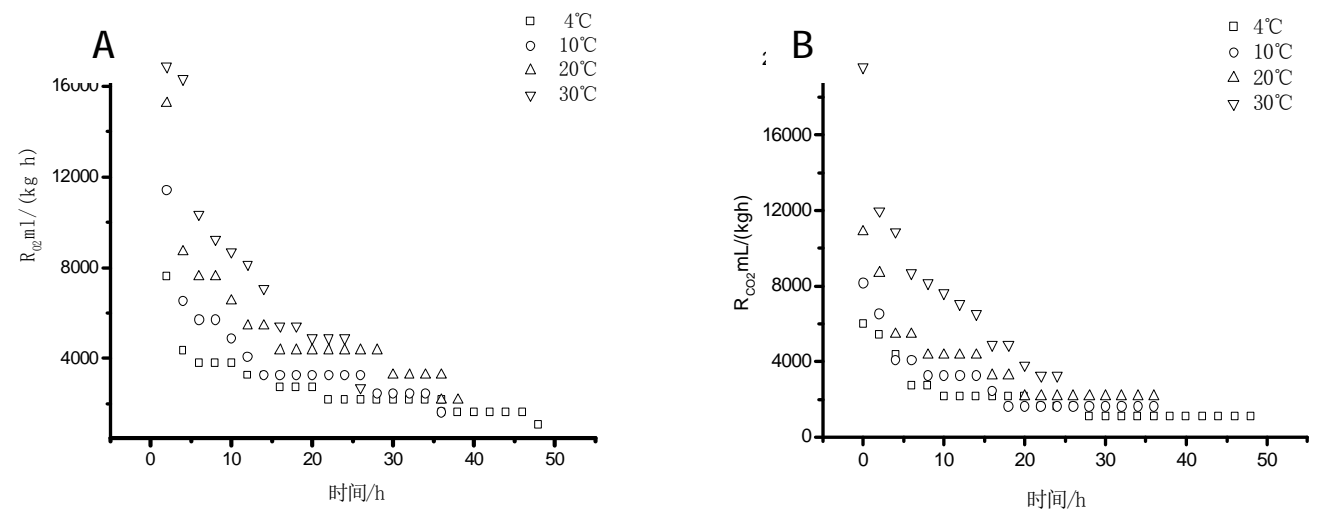

Fig 2 Changes of the respiratory rate $\mathrm{R}_{\mathrm{O} 2}(\mathrm{~A})$ and $\mathrm{R}_{\mathrm{CO} 2}(\mathrm{~B})$ of fresh-cut Purple cabbage at different temperature

\section{Respiratory rate model}

$$
\frac{1}{R}=\frac{1}{V_{m}}+\frac{K_{m}}{V_{m}} \cdot \frac{1}{\left[O_{2}\right]}+\frac{\left[\mathrm{CO}_{2}\right]}{K_{i} V_{m}}
$$

Equation 4 obtained by Multiple regression of the experimental of equation 3 , and then using the Datafit 9.0 (Oakdale Engineering, Oakdale, USA) to solve the parameter fitting. Parameter values are shown in table 1:

Table1 Estimates of enzyme kinetic model of fresh-cut Purple cabbage different temperatures

\begin{tabular}{cccccc}
\hline & $\mathrm{T} /{ }^{\circ} \mathrm{C}$ & $\mathrm{Vm} \mathrm{mL} /(\mathrm{kg} \cdot \mathrm{h})$ & $\mathrm{Km}$ & $\mathrm{Ki}$ & $\mathrm{R}^{2}$ \\
\hline \multirow{6}{*}{$\mathrm{RO}_{2}$} & $4{ }^{\circ} \mathrm{C}$ & 1963.648 & 17.77 & -6707.67 & 0.8670 \\
& $10{ }^{\circ} \mathrm{C}$ & 1759.083 & 0.740 & -22885.2 & 0.8454 \\
& $20{ }^{\circ} \mathrm{C}$ & 2175.343 & 0.128 & -34248.2 & 0.8501 \\
& $30{ }^{\circ} \mathrm{C}$ & 2630.046 & 0.068 & -54963.3 & 0.8834 \\
& $4{ }^{\circ} \mathrm{C}$ & 803.853 & -1.316 & -10622.9 & 0.9108 \\
$\mathrm{RCO}_{2}$ & $10{ }^{\circ} \mathrm{C}$ & 1109.15 & -3.080 & -29449.9 & 0.8897 \\
& $20{ }^{\circ} \mathrm{C}$ & 1597.399 & -0.024 & -27750.6 & 0.8904 \\
& $30{ }^{\circ} \mathrm{C}$ & 2485.643 & 0.0451 & -52461.2 & 0.9715 \\
\hline
\end{tabular}

Table 1 reflects three fitting parameters of fresh cut purple cabbage with the change of temperature. The value of $\mathrm{Vm}$ is lower under the condition of $4{ }^{\circ} \mathrm{C}$ than other tempretures, which shows that low temperature can effectively control the fresh cut respiratory rate of purple cabbage. The no competitive Michaelis - Menten equation have a good fitting. EF innegan ${ }^{[8]}$ using Michaelis Menten equation, studied the relationship between gas component in fresh cut pineapple package and it's respiratory rate, the results achieve well validation. Susanna $C^{[9]}$ apply this equaton and with kale as the research object,,describe the relationship between the content and respiration rate of gas inside the bag, the correlation coefficient of 0.96 . In this experiment, the determination 
coefficient $\mathrm{R}^{2}$ is more than 0.84 , so Non-competitive Michaelis - Menten equation is effective characterization of gas composition and respiration rate relationship.

\section{Conclusions}

1.The respiration rate of fresh-cut purple cabbage remarkable depend on tempreture, which increase with the tempreture rise;

2. Low oxygen and high carbon dioxide environment restrain respiratory rate of fresh cut purple cabbage, which is helpful to prolong the shelf life.

3. Establish the respiration rate model of fresh-cut cabbage that based on enzyme kinetics noncompetitive Michaelis - Menten equation, which reflect the relationship between gas component and respiratory rate. The correlation coefficient is more than 0.84 , and model parameters changes with the temperature, but no obvious regularity. It provide reference parameters for its gas packaging design.

\section{Acknowledgements}

This work was supported by China Agriculture Research System (CARS-25)

\section{References}

[1] Xu Wenda. Journal of food industry, 1999, (3) : 35-38

[2] Xue-jie zhang zhi-hua ye. Journal of food science, 2010, 31 (9) : 399-404.

[3] Song Y, Kim H K, Yam K L.:Journal of the American Society for Horticultural Science, 1992, 117(6): $925-929$

[4]Lee D S, Hagar P E, Lee J. Journal of Food Science, 1991, 56(6): 1 580 1 585

[5]Peppelenbos H W, Tijskens L M M , Van't Leven J, et al.Postharvest Biology Technology, 1996, 9: $283-285$

[6] Mathooko F M. Postharvest Biology and Technology, 1999, 9(3): 247-264

[7] Maneerat C. Tongta, A. Kanlayanarat, S. \& Wongs-Aree, C. (1997). In J. R. Gorny (Ed.), Proceedings of the 7th internationalcontrolled atmosphere research conference: Vol. 5 (pp. 191197), Davis, CA, USA.

[8] E. Finnegan, P.V. Mahajan, M. O’Connell, et al. Postharvest Biology and Technology, 2013, 79: 47-53

[9]Susana C. Fonseca, Fernanda A.R. Oliveira, Jeffrey K. Brecht. Journal of Food Engineering, 2002, (52): 99-119 